\title{
An Epidemiological Model Investigating the Association between Mothers Nutritional Status and Low Birth Weight in India
}

\author{
Dharmendra Kumar Dubey*, Dilip C. Nath \\ Department of Statistics, Gauhati University, Guwahati, India \\ Email: *dubey.dharm@gmail.com, dillipc.nath@gmail.com
}

Received 23 December 2015; accepted 22 February 2016; published 25 February 2016

Copyright (C) 2016 by authors and Scientific Research Publishing Inc.

This work is licensed under the Creative Commons Attribution International License (CC BY). http://creativecommons.org/licenses/by/4.0/

(c) (7) Open Access

\begin{abstract}
Introduction: Low birth weight (LBW) is the dominating risk factor for infant morbidity and mortality. LBW infants were three times more likely than normal birth weight infants to have neuro developmental complications and congenital abnormalities. The World Health Organization (WHO) has defined the term Low Birth Weight (LBW) as birth weight less than 2500 grams. Objective: To develop epidemiological model investigating the association between mother's nutritional status and low birth weight in India. Data and Methods: Third round of the National Family Health Survey (NFHS-3) data collected during 2005-2006 is used for this study. This data provides a comprehensive picture of population and health conditions in India. To check the association between variables coefficient of contingency was calculated and multivariable logistic regression model was applied to check independent effect of covariates. Univariate, bivariate and multivariable logistics regression model has been developed to investigate the association between mother's nutritional status and low birth weight in India. Adjusted odds ratios were calculated with $95 \%$ confidence interval. Conclusion: The prevalence of low birth weight was observed high among those women who were underweight, anemic, never visited for any ANC checkup. Emphasis needs to be given to maternal nutritional factors which are more persistent across India than the impact of other factors on birth weight. This can be done by selectively targeting interventions to improve nutrition.
\end{abstract}

\section{Keywords}

Low Birth Weight, BMI, Anemia, ANC

\footnotetext{
${ }^{*}$ Corresponding author.
} 


\section{Introduction}

Low birth weight is a strong predictor of an individual baby's survival. Infant mortality is a major public health problem in India. Low birth weight infant remains at much higher risk of mortality than the infant with normal weight at birth. Low birth weight (LBW) is the dominating risk factor for infant morbidity and mortality. LBW infants were three times more likely than normal birth weight infants to have neuro developmental complications and congenital abnormalities [1]. The prevalence of low birth weight (LBW) is higher in Asia than elsewhere, predominantly because of under nutrition of the mother prior to and during pregnancy [2]. Pregnancy outcome is worst in babies from mothers with low body mass index as compared to healthy weight mothers with respect to increased incidence of preterm birth, lower birth weight and increased neonate mortality [3].

Mothers' nutritional status is the most important determinant of newborn children's birth weight. Mothers' BMI impact was more pervasive across India than the impact of other factors on birth weight [4]. Low birth weight is a key indicator of the health trajectory of a child. In addition, to being an intrinsic endpoint, low birth weight is associated with increased risk of numerous adverse health outcomes in childhood and adulthood. Birth weight is a key variable for measuring the quality of the prenatal medical and social environment as well as predicting future individual health outcomes [5]. Low Birth Weight (LBW $<2.5 \mathrm{~kg}$ ) has been a problem of constant worry in the world, especially in developing countries like India [6]. Low birth weight babies are more likely to have disabilities in form of developmental delay poor growth and mental disabilities. For reducing the prevalence of low birth weight, public health strategy needs to focus attention on better maternal nutrition and education [7].

Low birth weight (LBW) is a major public health problem in many developing countries, especially in India. The problem of LBW is multidimensional, and it needs an integrated approach incorporating medical, social, economical and educational measures to address issue [8]. Socio-demographic and maternal characteristics were examined and associated with the LBW [9]. The burden of low birth weight deliveries are associated with inadequate ANC service utilization and unwanted pregnancy [10]. The maternal risk factors associated with low birth weight babies. The most common causes of morbidity and mortality were found in low birth weight babies [11]. Low birth weight proportion was higher in teenage pregnancies \& primiparous women [12]. Healthy diet providing before conception and throughout pregnancy had no overall effect on birth weight [13].

The major challenges in the field of public health is to identify the factors influencing low birth weight [14]. The importance of pre-pregnancy screening, early antenatal booking and proper identification of high riskmother needs to be strengthened and enforced in effort to reduce incidence of LBW infants [15]. Thus, LBW provides a target for interventions to improve infant survival. The prevention of LBW may be an explicit part of public health policy to decrease infant mortality. In this context, it is important to understand the various factors which are associated with the LBW in India. This study thus provides a national focus and examines the relationship between a number of proximate factors and low birth weight among Indian children. In particular, we investigate the role of mothers' nutritional status measured by their body mass index in determining the birth weight of their most recent births. We also explore the variation in the effect of maternal nutritional status on birth weight among the various states in India. Research questions: i) Do the women with poor nutritional status (measured in terms of body mass index) are more likely to produce children of low birth weight? ii) Do the women with poor nutritional status (measured in terms of anemia) are more likely to produce children of low birth weight? Objective of the Study: To develop epidemiological model investigating the association between mother's nutritional status and low birth weight in India.

\section{Material and Methods}

Third round of the National Family Health Survey (NFHS-3) data conducted during 2005-06 was used to fullfil the objective of the study. It provides a comprehensive picture of population and health conditions in India. Birth weight was used as dependent variable "Low birth weight" means children weighted less than 2.5 kilogrammes otherwise normal birth weight. In general, lower the weight, the higher a baby's risk of death. Low birth weight is associated with poor outcomes later in life. If LBW is caused by either preterm delivery or fetal growth retardation, then LBW is presumably completely preventable. Birth weight is usually divided for analysis into "low birth weight (LBW)" and "normal" birth weight. There were four epidemiological models developed. The significant factors identified in the univariate analysis were further examined using bivariate, trivarivate and Multivariable logistic regression models to estimate the effect of nutritional indicator body mass index (BMI) 
and other proximate determinants on the likelihood of having a low birth weight baby [16]. The coefficient of contingency (as suggested by Karl Pearson) was also calculated for association between low birth weight and explanatory variables.

Model-I: An univariate logistic regression model has been developed wherein birth weight category (LBW = 1 and NBW $=0$ ) was used as outcome variable and nutritional factor body mass index (BMI $=x_{1}$ ) considered as predictor variable.

Equation of this epidemiological model is:

$$
\log [p /(1-p)]=b_{0}+b_{1} x_{1}
$$

where $b_{1}$ was the regression coefficients and $\log [p /(1-p)]$ is called log odds or logit of the event.

Model-II: A bivariate logistic regression model has been developed wherein birth weight category (LBW = 1 and NBW $=0$ ) was used as outcome variable and BMI $=x_{1}$ and Anemia $=x_{2}$ considered as predictor variable.

Equation of the epidemiological model is:

$$
\log [p /(1-p)]=b_{0}+b_{1} x_{1}+b_{2} x_{2}
$$

where $b_{1}, b_{2}$, bivariate regression coefficients and $\log [p /(1-p)]$ is called log odds or logit of the event.

Model-III: In model 3, we used three explanatory variables. In terms of three maternal factors trivariate logistic regression model has developed wherein birth weight category (LBW $=1$ and NBW= 0 ) was used as outcome variable and $\mathrm{BMI}=x_{1}$, Anaemia $=x_{2}$ and Antenatal care $=x_{3}$ considered as predictor variable.

Equation of the epidemiological model is:

$$
\log [p /(1-p)]=b_{0}+b_{1} x_{1}+b_{2} x_{2}+b_{3} x_{3}
$$

where $b_{1}, b_{2}, b_{3}$ were the logistic regression coefficients and $\log [p /(1-p)]$ is called log odds or logit of the event.

Model-IV: Here a multivariable logistic regression model has been developed wherein birth weight category (LBW $=1$ and NBW $=0$ ) was used as outcome variable and $x_{1}$ (Place of residence), $x_{2}$ (Age), $x_{3}$ (Wealth index), $x_{4}$ (Education), $x_{5}$ (Religion), $x_{6}$ (Caste), $x_{7}$ (Anaemia level), $x_{8}$ (Body mass index), $x_{9}$ (Antenatal care) and $x_{10}$ (Birth order) were considered as predictor variables.

Equation of the epidemiological model is:

$$
\log [p /(1-p)]=b_{0}+b_{1} x_{1}+b_{2} x_{2}+b_{3} x_{3}+b_{4} x_{4}+b_{5} x_{5}+b_{6} x_{6}+b_{7} x_{7}+b_{8} x_{8}+b_{9} x_{9}+b_{10} x_{10}
$$

where $b_{1}, b_{2}, b_{3}, \cdots, b_{10}$ are the logistic regression coefficients and $\log [p /(1-p)]$ is called log odds or logit of the event.

Above models were carried out for India and its Empowered Action Group (EAG) states including Assam. Third round of the National Family Health Survey included a special module on nutrition [17]. The women were selected using a complex multi-stage cluster sampling approach [17]. There were two weights in the data file to adjust for oversampling of respondents by certain states and categories, one for national level analysis and the other for state level analysis [17]. All the analyses presented here used the appropriate weight. We noted that NFHS -3 was designed to make estimates at both state and national level. Details of the dependent and predictors variable are briefed in the table number one for mother factors, child factor and socio-demographic factors.

Table 1 demonstrates the picture of created dummy variable from the original variables, which was used in analysis. The selection of variable was based on their availability in the data set. The proximate factors identified as a cause of low birth weight like, mother's factor, child factor and socio-demographic factors were considered in analysis. Mothers body mass index was divided into three categories, underweight (BMI < 18.5), normal weight $(18.5$ to $<25)$ and Overweight $(25 \&$ above) and it was considered as a nutritional indicator. Body mass index was a reliable indicator of chronic energy deficiency [18]. BMI was measured during the preconception period to examine the effect on low birth weight. In NFHS-3, survey only $34 \%$ of birth weight data was reported. Under the sub-categories of ANC visit it was found that $23 \%$ of mothers had never visited for ANC check-up. Other sub-categories of the variable is explained in Table 1. 
Table 1. Definition and classification of variables used in the analysis.

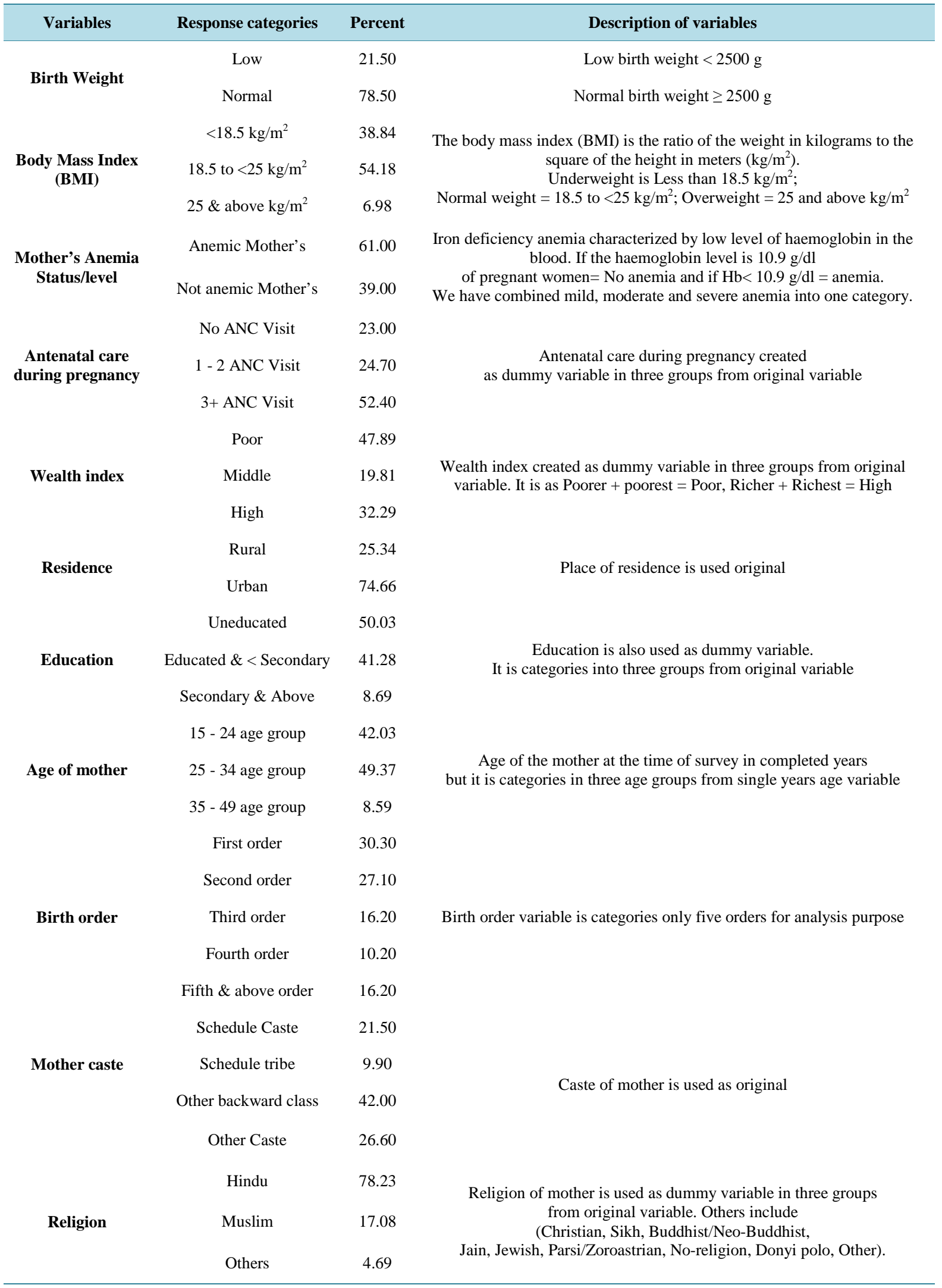




\section{Results}

Table 2 shows the percentage of the low birth weight under the sub categories of the predictor variables. The contingency coefficient was calculated for the association between low birth weight and explanatory variables. The prevalence of the low birth weight was found 22\% in India. Low birth weight was found $23 \%$ in rural and $19 \%$ in urban. In respect of age, highest prevalence of the LBW was found in early age group (24\%) in comparison to middle (20\%) \& older age group (17\%). In terms of wealth index, prevalence of LBW was found highest in poor (25\%) \& lowest in rich (19\%). In the category of education, low birth weight was found highly variable at different level of the education. Under the uneducated category LBW was found highest (26\%). In religion, LBW was highest in Hindu (22\%). In caste, LBW was found highest in schedule caste (24\%) comparable to schedule tribe (22\%) and OBC (21\%). In anemia level, LBW was shown high (23\%) in anemic mother in comparison to non anemic mother (21\%). In BMI, LBW was varied under sub-categories of the body mass index (BMI), highest (26\%) in underweight, moderate in normal weight $(21 \%)$ \& lowest in overweight (17\%). If mothers had never visited for antenatal checkup then LBW was found highest (33\%). In birth order, under the fifth and above birth order category LBW was found highest (26\%) and in second birth order it was lowest (20\%). Contingency of coefficients was found significant $(p<0.05)$ for all predictor variables except religion. Figure 1 was shown for prevalence of LBW out of total reported birth weight in NFHS-3 data set.

Table 3 reveals the scenario of low birth weight for every state. In Haryana, prevalence of LBW was found highest (33\%) and lowest was found in Mizoram (7\%). Punjab and Bihar were shown similar prevalence low birth weight (28\%). Himanchal and Uttar Pradesh were found 25\% LBW. Tripura was shown 27\% LBW and Maharashtra was found 22\% LBW. Orissa was shown 21\% LBW. Details are available in the same table.

Table 4 presents findings from logistics regression analysis using different models. In model 1, mothers’ nutrition measured by their body mass index (BMI); underweight mothers were $32 \%$ more likely to have a low birth weight baby than those mothers who weighed normal. In model 2, anemic mothers were $8 \%$ more likely to have LBW than not anemic and model was shown significant impact on the likelihood of having low birth weight babies. Therefore, mothers' nutritional status was a large independent and statistically significant effect on the birth weight of newborns. In model 3, those who were not visited for antenatal checkup increased 93\% more likely to have LBW than those who used the antenatal services frequently (3 or more visits). In model 4, those who never visited for any ANC checkup also increased 73\% more likely to have LBW than used ANC checkup. Rural residents were 9\% more likely to have LBW than urban. Early age mothers were $41 \%$ more likely to have LBW than older age mothers. Uneducated mothers were $48 \%$ more likely to have LBW than those mothers were educated up to secondary and above level. Fifth and above birth order of baby was $21 \%$ more likely to have a low birth weight than first order of the baby.

Table 5 represents the adjusted logistic regression model for empowered action group (EAG) including Assam states. The critical relevance of mothers nutritional status was emphasized by the fact that in all the EAG including Assam states mothers, who were underweight were more likely to have LBW than normal weight. Although the effect was statistically significant found in Bihar, Orissa \& Assam. Mothers who were anemic were more likely to have LBW in all EAG states except UP \& MP. Although the effect was statistically significant found in Orissa and Rajasthan. Mothers who had never visited for ANC checkup were more likely to have LBW than those who visited in all EAG states except Orissa and Assam (for more detail see Table 5).

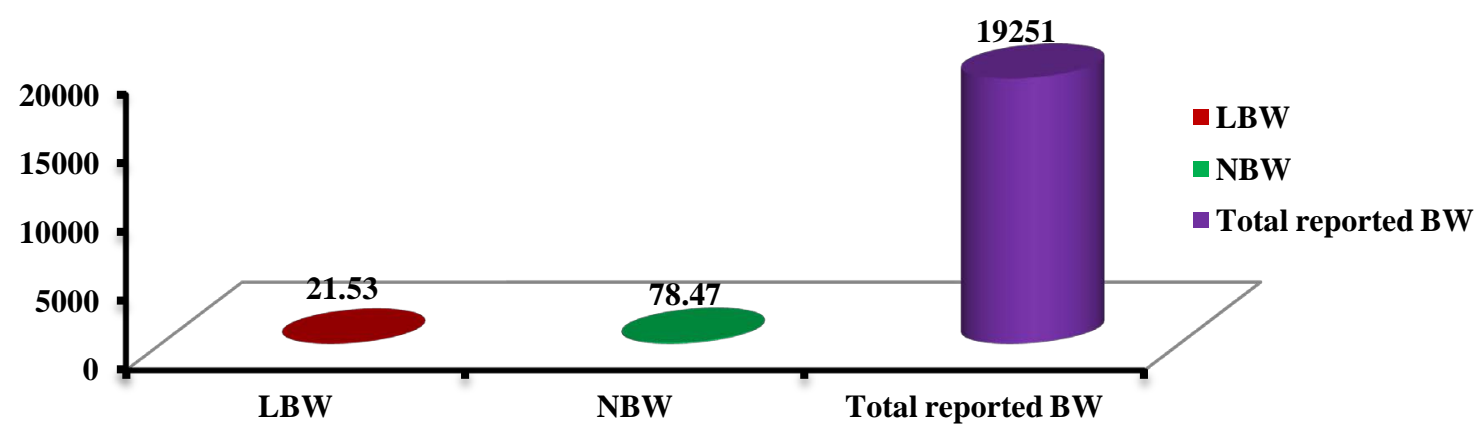

Figure 1. Prevalence of low birth weight in India. 
Table 2. Shows the prevalence of the low birth weight according to different sub-categories of the background characteristics.

\begin{tabular}{|c|c|c|c|c|}
\hline Predictors variable & LOW (<2500 g) & Normal $(\leq 2500$ g) & Total & $p$-value \\
\hline Place of residence & & & & 0.0 \\
\hline Urban & $19.34(1668)$ & 80.66 (6956) & 8624 & \\
\hline Rural & $23.32(2478)$ & 76.68 (8147) & 10,625 & \\
\hline Age & & & & 0.0 \\
\hline $15-24$ & $23.99(2021)$ & $76.01(6402)$ & 8423 & \\
\hline $25-34$ & $19.91(1960)$ & 80.09 (7882) & 9842 & \\
\hline $35-49$ & $16.79(165)$ & $83.21(818)$ & 983 & \\
\hline Wealth index & & & & 0.0 \\
\hline Poor & $25.38(1055)$ & $74.62(3101)$ & 4156 & \\
\hline Middle & $23.69(889)$ & 76.31 (2864) & 3753 & \\
\hline Rich & $19.42(2202)$ & 80.58 (9138) & 11340 & \\
\hline Education & & & & 0.0 \\
\hline No Education & $26.22(1034)$ & $73.78(2910)$ & 3944 & \\
\hline Educated \& $<$ secondary & 21.95 (2483) & 78.05 (8827) & 11,310 & \\
\hline Secondary and above & $15.74(629)$ & $84.26(3366)$ & 3995 & \\
\hline Religion & & & & 0.1 \\
\hline Hindu & $21.84(3351)$ & $78.16(11,992)$ & 15,343 & \\
\hline Muslim & $20.18(529)$ & 79.82 (2093) & 2622 & \\
\hline Others & $20.78(267)$ & 79.22 (1018) & 1285 & \\
\hline Caste & & & & 0.0 \\
\hline Schedule caste & $23.52(784)$ & 76.48 (2549) & 3333 & \\
\hline Schedule tribe & $23.31(266)$ & $76.69(875)$ & 1141 & \\
\hline Other backward class & 21.25 (1578) & $78.75(5845)$ & 7423 & \\
\hline General Caste & $20.60(1402)$ & 79.40 (5419) & 6821 & \\
\hline Anemia level & & & & 0.0 \\
\hline Anemic & $22.60(2277)$ & 77.40 (7776) & 10,053 & \\
\hline Not anemic & $20.73(1670)$ & 79.27 (6385) & 8055 & \\
\hline BMI level & & & & 0.0 \\
\hline Under weight (<18.5 Kg) & $25.63(1454)$ & 74.37 (4219) & 5673 & \\
\hline Normal (18.5 - 24.99 Kg) & 20.72 (2119) & 79.28 (8108) & 10,227 & \\
\hline Overweight (25\& above) & $17.18(448)$ & 82.82 (2159) & 2607 & \\
\hline Antenatal care & & & & 0.0 \\
\hline No ANC Visit & 33.00 (179) & $67.00(364)$ & 543 & \\
\hline 1 - 2 & $26.00(461)$ & $74.00(1310)$ & 1771 & \\
\hline $3+$ & 19.50 (2429) & $80.50(10,022)$ & 12,451 & \\
\hline Birth order & & & & 0.0 \\
\hline $1^{\text {st }}$ birth order & 22.30 (1912) & 77.70 (6645) & 8557 & \\
\hline $2^{\text {nd }}$ birth order & $19.80(1261)$ & $80.20(5121)$ & 6382 & \\
\hline $3^{\text {rd }}$ birth order & $21.30(513)$ & $78.70(1890)$ & 2403 & \\
\hline $4^{\text {th }}$ birth order & $22.20(226)$ & $77.80(793)$ & 1019 & \\
\hline $5^{\text {th }} \&$ above birth order & $26.40(234)$ & $73.60(654)$ & 888 & \\
\hline Total & $21.53(4146)$ & $78.47(15,103)$ & 19,249 & \\
\hline
\end{tabular}


Table 3. Shows the prevalence of the low birth weight according to every state of India.

\begin{tabular}{|c|c|c|c|}
\hline State & LOW $(<2500$ g) & Normal $(\leq 2500 \mathrm{~g})$ & Total \\
\hline [JM] Jammu and Kashmir & $19.10(13)$ & $80.90(55)$ & 68 \\
\hline [HP] Himachal Pradesh & $24.50(27)$ & $75.50(83)$ & 110 \\
\hline [PJ] Punjab & $27.80(125)$ & $72.20(325)$ & 450 \\
\hline [UC] Uttaranchal & $24.20(24)$ & $75.80(75)$ & 99 \\
\hline [HR] Haryana & $32.80(101)$ & $67.20(207)$ & 308 \\
\hline [DL] Delhi & $26.60(71)$ & $73.40(196)$ & 267 \\
\hline [RJ] Rajasthan & $27.40(202)$ & $72.60(534)$ & 736 \\
\hline [UP] Uttar Pradesh & $25.20(245)$ & $74.80(729)$ & 974 \\
\hline [BH] Bihar & $27.50(200)$ & $72.50(527)$ & 727 \\
\hline [SK] Sikkim & $7.70(01)$ & $92.30(12)$ & 13 \\
\hline [AR] Arunachal Pradesh & $15.80(03)$ & $84.20(16)$ & 19 \\
\hline [NA] Nagaland & $10.00(01)$ & $90.00(09)$ & 10 \\
\hline [MN] Manipur & $13.20(07)$ & $86.80(46)$ & 53 \\
\hline [MZ] Mizoram & $7.10(03)$ & 92.90 (39) & 42 \\
\hline [TR] Tripura & $26.80(19)$ & $73.20(52)$ & 71 \\
\hline [MG] Meghalaya & $18.00(11)$ & $82.00(50)$ & 61 \\
\hline [AS] Assam & $19.40(56)$ & $80.60(232)$ & 288 \\
\hline [WB] West Bengal & $22.90(409)$ & 77.10 (1376) & 1785 \\
\hline [JH] Jharkhand & $19.20(61)$ & $80.80(256)$ & 317 \\
\hline [OR] Orissa & $20.50(147)$ & $79.50(570)$ & 717 \\
\hline [CH] Chhattisgarh & $17.40(47)$ & $82.60(223)$ & 270 \\
\hline [MP] Madhya Pradesh & $23.40(200)$ & 76.60 (656) & 856 \\
\hline [GJ] Gujarat & $22.00(305)$ & $78.00(1081)$ & 1386 \\
\hline [MH] Maharashtra & $22.10(685)$ & $77.90(2411)$ & 3096 \\
\hline [AP] Andhra Pradesh & $19.30(381)$ & $80.70(1588)$ & 1969 \\
\hline [KA] Karnataka & $18.70(317)$ & $81.30(1378)$ & 1695 \\
\hline [GO] Goa & $21.70(10)$ & $78.30(36)$ & 46 \\
\hline [KE] Kerala & $16.20(160)$ & $83.80(830)$ & 990 \\
\hline [TN] Tamil Nadu & $17.20(315)$ & $82.80(1513)$ & 1828 \\
\hline Total & $21.53(4146)$ & 78.47 (15105) & 19,251 \\
\hline
\end{tabular}

Table 4. Estimated effects of the proximate factors on birth weight, India. ( $p<0.05$ and confidence intervals are given for model 4).

\begin{tabular}{|c|c|c|c|c|c|c|}
\hline \multirow{2}{*}{$\begin{array}{c}\text { Predictors variable } \\
\text { Place of residence }\end{array}$} & \multicolumn{4}{|c|}{ Estimated Odds Ratio } & \multicolumn{2}{|c|}{ 95\% C.I. } \\
\hline & Model 1 & Model 2 & Model 3 & Model 4 & Lower & Upper \\
\hline Urban & & & & 1.00 & & \\
\hline Rural & & & & 1.09 & 0.99 & 1.20 \\
\hline \multicolumn{7}{|l|}{ Age of Women } \\
\hline $15-24$ & & & & 1.41 & 1.13 & 1.74 \\
\hline $25-34$ & & & & 1.15 & 0.94 & 1.40 \\
\hline $35-49$ & & & & 1.00 & & \\
\hline wealth index & & & & & & \\
\hline
\end{tabular}




\section{Continued}

Poor

1.01

0.89

1.16

Middle

1.09

0.97

1.22

Rich

1.00

Education of women

\section{No Education}

Educated \& $<$ secondary

Secondary and above

Religion of women

\section{Hindu}

Muslim

Others

Caste

Schedule caste

Schedule tribe

Other backward class

General Caste

Anemia level

\section{Anemic}

Not anemic

BMI level
Normal (18.5 - 24.99 Kg)

Overweight (25 \& above)

Antenatal care

No ANC Visit

$$
1-2
$$

$3+$

Birth order

$1^{\text {st }}$ birth order

$2^{\text {nd }}$ birth order

$3^{\text {rd }}$ birth order

$4^{\text {th }}$ birth order

$5^{\text {th }} \&$ above birth order

-2 log likelihood

Model chi square

N

\section{$19,283.45$}

88.41

$18,862.95$

$14,132.63$

93.29

19,336

20,080
1.32

1.00

0.79
$1.08^{*}$

1.00

1.31

1.00

0.78
1.48

1.35

1.00

0.83

0.75

1.00

1.05

0.93

0.95

1.00
1.06

1.00

1.33

1.00

0.81

1.93

1.37

1.00
1.25

1.19

1.74

1.53

0.70

0.98

0.60

0.93

.05

0.92

1.19

0.77

1.12

0.86

1.05

1.03

0.95

1.13

1.00

1.25

1.14

1.37

1.00

0.93

0.81

1.07
1.73

1.25

1.00

1.00

0.90

0.91

0.96

1.21

1.42

2.11

1.10

1.42

$3,662.49$

245.87

14,345 
Table 5. Estimated effects (adjusted odd ratios) of the proximate determinants on birth weight by Empowered Action Group (EAG) states including Assam in India. $\left({ }^{*} p<0.05\right)$.

\begin{tabular}{|c|c|c|c|c|c|c|c|c|c|}
\hline \multirow{2}{*}{ Variables } & \multicolumn{9}{|c|}{ Empowered Action Group (EAG) States } \\
\hline & UP & MP & Bihar & UK & $\mathrm{CH}$ & $\mathrm{JH}$ & Orissa & RJ & Assam \\
\hline \multicolumn{10}{|l|}{ Anemia level } \\
\hline Anemic & 0.97 & 0.84 & 1.02 & 1.14 & 1.73 & 1.37 & $1.64^{*}$ & $1.83^{*}$ & 1.20 \\
\hline Not anemic & 1.00 & 1.00 & 1.00 & 1.00 & 1.00 & 1.00 & 1.00 & 1.00 & 1.00 \\
\hline \multicolumn{10}{|l|}{ BMI level } \\
\hline Under weight (<18.5 Kg) & 1.39 & 1.36 & $1.65^{*}$ & 2.87 & 1.20 & 2.07 & $1.77^{*}$ & 1.15 & $2.73^{*}$ \\
\hline Normal (18.5 - 24.99 Kg) & 1.00 & 1.00 & 1.00 & 1.00 & 1.00 & 1.00 & 1.00 & 1.00 & 1.00 \\
\hline Overweight (25\& above) & $0.47^{*}$ & $0.33^{*}$ & 0.48 & 0.95 & 1.27 & 0.54 & 1.38 & 0.68 & 1.60 \\
\hline \multicolumn{10}{|l|}{ Antenatal care } \\
\hline No ANC Visit & 1.90 & 1.87 & 1.43 & 4.76 & 2.41 & 2.57 & 0.65 & 1.92 & 0.74 \\
\hline $1-2$ & 1.01 & 0.81 & 1.32 & 1.00 & 1.70 & 0.60 & 0.94 & 1.48 & 0.75 \\
\hline $3+$ & 1.00 & 1.00 & 1.00 & 1.00 & 1.00 & 1.00 & 1.00 & 1.00 & 1.00 \\
\hline \multicolumn{10}{|l|}{ Birth order } \\
\hline $1^{\text {st }}$ birth order & 1.00 & 1.00 & 1.00 & 1.00 & 1.00 & 1.00 & 1.00 & 1.00 & 1.00 \\
\hline $2^{\text {nd }}$ birth order & 0.71 & 0.84 & 1.28 & 1.12 & 0.92 & 0.96 & 0.86 & 0.93 & 0.68 \\
\hline $3^{\text {rd }}$ birth order & 0.72 & 0.55 & 0.81 & 1.73 & 1.22 & $0.15^{*}$ & 0.62 & 1.54 & 0.36 \\
\hline $4^{\text {th }}$ birth order & $0.23^{*}$ & 0.57 & 0.60 & 1.60 & 1.15 & 0.30 & 1.04 & 0.86 & 0.72 \\
\hline $5^{\text {th }} \&$ above birth order & 0.63 & 0.90 & $2.12^{*}$ & 0.46 & 0.47 & 0.54 & 1.03 & 1.02 & 1.40 \\
\hline-2 log likelihood & 683.98 & 661.60 & 570.61 & 74.25 & 182.61 & 188.10 & 534.84 & 597.78 & 214.30 \\
\hline Model Chi square & 27.46 & 15.51 & 28.70 & 4.37 & 6.22 & 17.03 & 14.23 & 18.49 & 11.03 \\
\hline $\mathbf{N}$ & 533 & 787 & 266 & 214 & 323 & 235 & 538 & 327 & 298 \\
\hline
\end{tabular}

\section{Discussion and Conclusions}

The objective of the study is to develop the epidemiological model investigating the association between mother's nutritional status and low birth weight in India. The prevalence of the low birth weight was found $22 \%$ in India. Contingency of coefficients was found significant $(p<0.05)$ for all predictors variable except religion. The most important socio-economic influences on the determination of low birth weight in India [19]. Mothers' nutrition, measured by their body mass index (BMI) have the greatest effect. Underweight mothers were more likely to have a low birth weight baby than those women who weighed normal. Anemic mothers were more likely to have LBW than not anemic and model was shown significant impact on the likelihood of having low birth weight babies. Existing evidence suggests that factors associated with underweight, obesity or overweight are very similar, information and health education programs for women are needed to help them to understand the components of a healthy diet and to ensure adequate access to health services [20].

Prevalence of LBW can be reduced by increasing the gestational age, regular antenatal checkup, balanced diet during antenatal period, adequate rest during antenatal period, and avoiding the tobacco chewing [7]. Those who did not visit for antenatal checkup were more likely to have LBW than those who visited for antenatal services. Birth weight was low in undernourished pregnant women and women were unhealthy. So health policies should aim at early detection and effective management of under nutrition to reduce the burden of Low birth weight [21]. Higher birth order babies were more likely to have a low birth weight than first ordered babies. The critical relevance of mothers nutritional status was emphasized by the fact that in all the EAG including Assam state 
mothers, who were underweight were more likely to have LBW than normal weight. Literature suggests that increasing BMI and the gestational weight gain was found to have strong association with the birth weight of the newborns among the ethnic community [22].

The magnitude of the effect varies as we included other proximate determinants in the model: body mass index (BMI), antenatal care, ANC, education of mother, birth order, age of mother and other factors. All these variables had a significant impact on the likelihood of low birth weight. Across EAG including Assam states level analysis were also showed that mothers' nutritional status had more consistent relationship with low birth weight than any other sub-categories of covariate included in the analysis. For instance, underweight mothers increased the risk of low birth weight almost three times in Uttaranchal state. Other papers addressing similar issue reveals that role of mothers' nutritional status accounted for over $50 \%$ of the low birth weight babies in the developing world [23] [24].

The results of this study suggest that low birth weight is more common among those women who are underweight, compared to women with normal BMI. Further, this was found low among non-anemic mothers compared to anemic mothers. The prevalence of low birth weight can be reduced by selectively targeting interventions to improve nutritional status of mothers (BMI), their anemia level including educational status of women.

\section{Conflict of Interest}

None.

\section{References}

[1] Singh, Chouhan and Sidhu (2009) Maternal Factors for Low Birth Weight Babies. Medical Journal Armed Forces India (MJAFI), 65.

[2] Muthayya, S. (2009) Maternal Nutrition \& Low Birth Weight-What Is Really Important? Indian Journal of Medical Research, 130, 600-608.

[3] Kalk, P., et al. (2009) Impact of Maternal Body Mass Index on Neonatal Outcome. European Journal of Medical Research, 14, 216-222.

[4] Dharmalingam, A. (2010) Nutritional Status of Mothers and Low Birth Weight in India. Maternal and Child Health Journal, 14, 290-298. http://dx.doi.org/10.1007/s10995-009-0451-8

[5] Subramanyam, M.A., Ackerson, L.K. and Subramanian, S.V. (2010) Patterning in Birth Weight in India: Analysis of Maternal Recall and Health Card Data. PLoS One, 5, e11424. http://dx.doi.org/10.1371/journal.pone.0011424

[6] Dasgupta, A. and Basu, R. (2011) Determinants of Low Birth Weight in a Block of Hooghly, West Bengal: A Multivariate Analysis. International Journal of Biological and Medical Research, 2, 838-842.

[7] Gagan, A., Sartaj, A., Kapil, G., Kumar, V., Parul, G., et al. (2012) Maternal Risk Factors Associated with Low Birth Weight Neonates in a Tertiary Care Hospital, Northern India. Journal of Community Medicine \& Health Education, 2, 177.

[8] Metgud, C.S., Naik, V.A. and Mallapur, M.D. (2012) Factors Affecting Birth Weight of a Newborn—A Community Based Study in Rural Karnataka, India. PLOS ONE, 7, e40040. http://dx.doi.org/10.1371/journal.pone.0040040

[9] Choudhary, et al. (2014) Factors Associated with Low Birth Weight among Newborns in an Urban Slum Community in Bhopal. http://www.ijph.in

[10] Teklehaimanot, N., Hailu, T. and Assefa, H. (2014) Prevalence and Factors Associated with Low Birth Weight in Axum and Laelay Maichew Districts, North Ethiopia: A Comparative Cross Sectional Study. International Journal of Nutrition and Food Sciences, 3, 560-566. http://dx.doi.org/10.11648/j.ijnfs.20140306.21

[11] Maheswari, K. and Behera, N. (2014) Maternal Risk Factors and Outcome of Low Birth Weight Babies Admitted to a Tertiary Care Teaching Hospital. Current Pediatric Research, 18, 69-72.

[12] Gosavi, S.V. and Koparkar, A.R. (2014) Predictors of Low Birth Weight: A Retrospective Study from Rural India. International Journal of Contemporary Pediatrics, 1, 7-9. http://www.ijpediatrics.com http://dx.doi.org/10.5455/2349-3291.ijcp20140503

[13] Potdar, R.D., Sahariah, S.A., Gandhi, M., Kehoe, S.H., Brown, N., Sane, H., et al. (2014) Improving Women’s Diet Quality Preconceptionally and during Gestation: Effects on Birth Weight and Prevalence of Low Birth Weight-A Randomized Controlled Efficacy Trial in India (Mumbai Maternal Nutrition Project). American Journal of Clinical Nutrition, 100, 1257-1268. http://dx.doi.org/10.3945/ajcn.114.084921

[14] Dandekar, R.H., Shafee, M. and Sinha, S.P. (2014) Prevalence and Risk Factors Affecting Low Birth Weight in a Dis- 
trict Hospital at Perambalur, Tamilnadu. Global Journal of Medicine and Public Health, 3.

[15] Sutan, R., Mohtar, M., Mahat, A.N. and Tamil, A.M. (2014) Determinant of Low Birth Weight Infants: A Matched Case Control Study. Open Journal of Preventive Medicine, 4, 91-99. http://dx.doi.org/10.4236/ojpm.2014.43013

[16] Hosmer, D.W. and Lemeshow, S. (2000) Applied Logistic Regression. 2nd Edition, Wiley, New York. http://dx.doi.org/10.1002/0471722146

[17] International Institute for Population Sciences (IIPS) and Macro International (2007) National Family Health Survey (NFHS-3), 2005-06: India: Volume II. IIPS, Mumbai.

[18] Shetty, P.S. and James, W.P. (1994) Body Mass Index: A Measure of Chronic Energy Deficiency in Adults. Food and Nutrition Paper No. 56, Food and Agricultural Organization, Rome.

[19] Bharati, P., Pal, M., Bandyopadhyay, M., Bhakta, A., Chakraborty, S. and Bharati, P. (2011) Prevalence and Causes of Low Birth Weight in India. Journal of Nutrition, 17, 301-313.

[20] Patil Ramesh, S. (2012) Study on Trend of Nutritional Status and Health Outcomes of Women. Indian Journal of Maternal \& Child Health, 14.

[21] Sharma, M. and Mishra, S. (2014) Effects of Maternal Health and Nutrition on Birth Weight of Infant. International Journal of Science and Research, 3, 855-858. www.ijsr.net

[22] Upadhyay, S., Biccha, R.P., Sherpa, M.T., Shrestha, R. and Panta, P.P. (2011) Association between Maternal Body Mass Index and the Birth Weight of Neonates. Nepal Medical College Journal, 13, 42-45.

[23] Kramer, M. (1987) Determinants of Low Birth Weight: Methodological Assessment and Meta-Analysis. Bulletin of the World Health Organization, 65, 663-737.

[24] Kramer, M. (1987) Intrauterine Growth and Gestational Duration Determinants. Paediatrics, 80, 502-511. 